\title{
Trends in State Funded Preschool in the United States: Findings from 10 Years of Policy Surveys
}

\author{
Steven Barnett Megan Carolan \\ National Institute for Early Education Research, Rutgers University \\ USA
}

\begin{abstract}
An annual survey by the National Institute for Early Education Research has traced state pre-K policy change in the United States since 2001. Such programs are only one part of a system that also includes a large federal program (Head Start) and a large private sector. The last decade was one of large changes in enrollment, policies relating to access and quality, and expenditures. Not all of these chances were positive, and it appears that the Great Recession had substantial negative impacts. Major trends in state pre-K include large enrollment growth at age 4, while enrollment at age 3 changed little, universal adoption of comprehensive early learning standards and, modestly, in program quality standards. On the downside, state expenditure per child fell by more than $\$ 1,000$ adjusting for inflation over 10 years. Some disadvantaged groups who might benefit most from high quality state pre-K have the least access, such as English language learners and Hispanic children. State policies show extreme variation, and the range increased over the decade. Some states moved to universal enrollment while others still have no program. State funding per child varies by almost $\$ 10,000$ per pupil from highest to lowest. Surveys such as this are an important tool for understanding how policy varies over time and geopolitical boundaries as well as examining equity in access to quality.
\end{abstract}

Key words: early childhood education and care, preschool, policy, ethnic minority children, special needs children.

\section{Introduction}

Correspondence regarding this article should be addressed to Steven Barnett, Director, National Institute for Early Education Research, Rutgers University, USA; Megan Carolan, Policy Research Coordinator, National Institute for Early Education Research, Rutgers University, USA. Electronic mail may be sent to sbarnett @nieer.org.

* Support for this work was provided by The Foundation for Child Development (FCD) as part of their preparation for their strategic planning process and by the U.S. Department of Education to the Center on Enhancing Early
For the last decade we have tracked the policies of state-funded preschool programs in the United States through an annual survey with the results published by the National Institute for

Learning Outcomes. We would like to thank Dr. Deborah Phillips, President of FCD, for numerous helpful suggestions. However, the authors alone are responsible for the analyses and views presented here. 
Early Education Research in the State Preschool Yearbook. This annual report, which started with the 2001-2002 school year, provides data on enrollment, policies relating to access and quality, and expenditures through the 20112012 school year for each of the 50 states. A goal of the Yearbook is to improve the public's knowledge and understanding of state efforts to educate young children, generate public interest and debate regarding pre-k policies, increase the political salience of pre-K policies, and facilitate cross-state comparisons to inform both the public and policy makers regarding what policies are like elsewhere. It also provides policy analysts with data that otherwise would not be readily available and comparable across states.

Our data document tremendous change in state pre-K over the decade, some of it good, and some not. The most dramatic change has been that states now serve nearly 30 percent of 4year-olds, slightly more than 30 percent when preschool special education is included. It now serves more than twice as many 4-year-olds as Head Start and more children than Head Start serves at all ages. In this report we detail major trends in state pre-K over the last decade and discuss their implications.

\section{Enrollment}

In 2001-2002, 690,891 children enrolled in state-funded pre-K programs, 14 percent of the nation's population of 4year-olds and 3 percent of 3-year-olds. By 2011-2012 this had nearly doubled to 1,332,663 children, 28 percent of 4-yearolds and 4 percent of 3-year-old. Figure 1 displays enrollment for each year by age and shows that enrollment at age 4

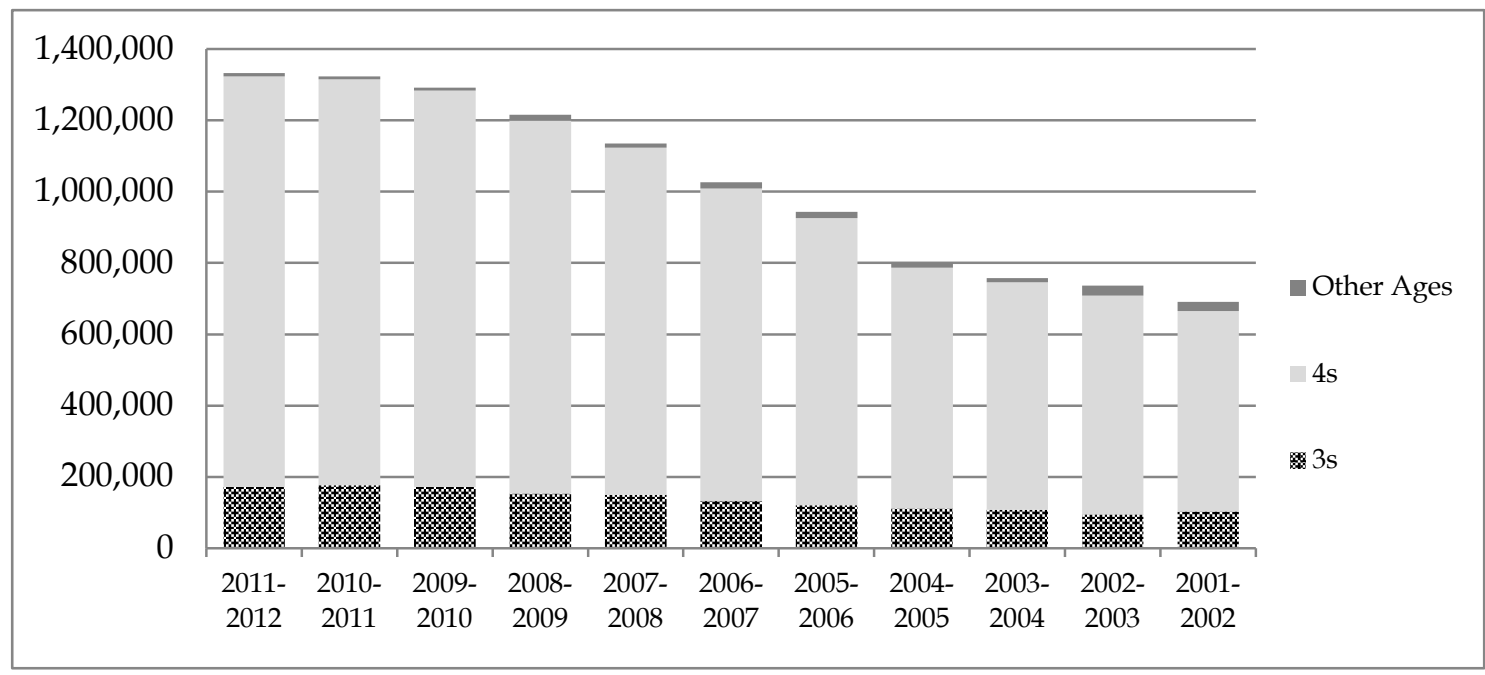

Figure 1. Enrollment growth by age from 2001-2002 to 2011-2012 
more than doubled accounting for the vast majority of growth in state pre-K. By age, enrollment increased by 589,533 at age 4 and 68,455 at age 3 . Note that a period of steady growth from 2004 to 2008 appears to have been halted by the impacts of the Great Recession on state revenues. Enrollment growth barely kept up with population growth in 2011-2012. Yet, because many programs target eligibility based on income and the recession pushed more families into poverty the percentage of the population eligible for state pre-K likely increased even more.

States increased enrollment by both expanding enrollment in existing programs and, to a lesser extent, creating new programs. Over the decade, the nation went from 42 programs in 37 states to 52 programs in 40 states as well as two in Washington, D.C. States create multiple programs for a variety of reasons that include differences in eligibility requirements, standards, funding sources, and provider types (e.g., public schools, private nonprofits, and faith based). This proliferation of programs within states can create confusion for the public regarding just what a state offers for both parents and taxpayers.

States that already fund one preschool program may create additional programs for several reasons. One is to serve a different population, typically with different standards. For example, Iowa added its Statewide Voluntary Preschool Program to expand eligibility to all children while maintaining its Shared
Visions program targeting at-risk students. In addition, new programs may be created to facilitate provision through faith-based and other private programs if the existing program is designed to serve children in public schools. Clearly, there is no one model for states to follow in creating or expanding a program, but it does make for a somewhat chaotic landscape in a field where separate silos (preschool, special education, Head Start, and child care) already present challenges.

Examining enrollment on a state by state basis, 30 states and the District of Columbia increased enrollment including 15 states plus D.C. that more than doubled the number of children served. Of course, this also implies that 20 states did not significantly increase enrollment and six of these saw enrollment fall over the decade, ranging from a 15 percent drop in enrollment in Minnesota to a 76 percent decrease in Ohio.

By the beginning of this decade 8 states and the District of Columbia served more than half of their 4-yearolds. D.C., Oklahoma and Florida offered pre-K to virtually every 4-yearold, albeit at extremely low standards in Florida, as we discuss later. Several other states have proposed to serve all children at age 4, including Georgia, New York, West Virginia, Iowa, and Illinois. In several of those states, budget woes exacerbated by the Great Recession appear to have derailed progress. And despite the overall progress, 20 states still served fewer than 1 in 10 


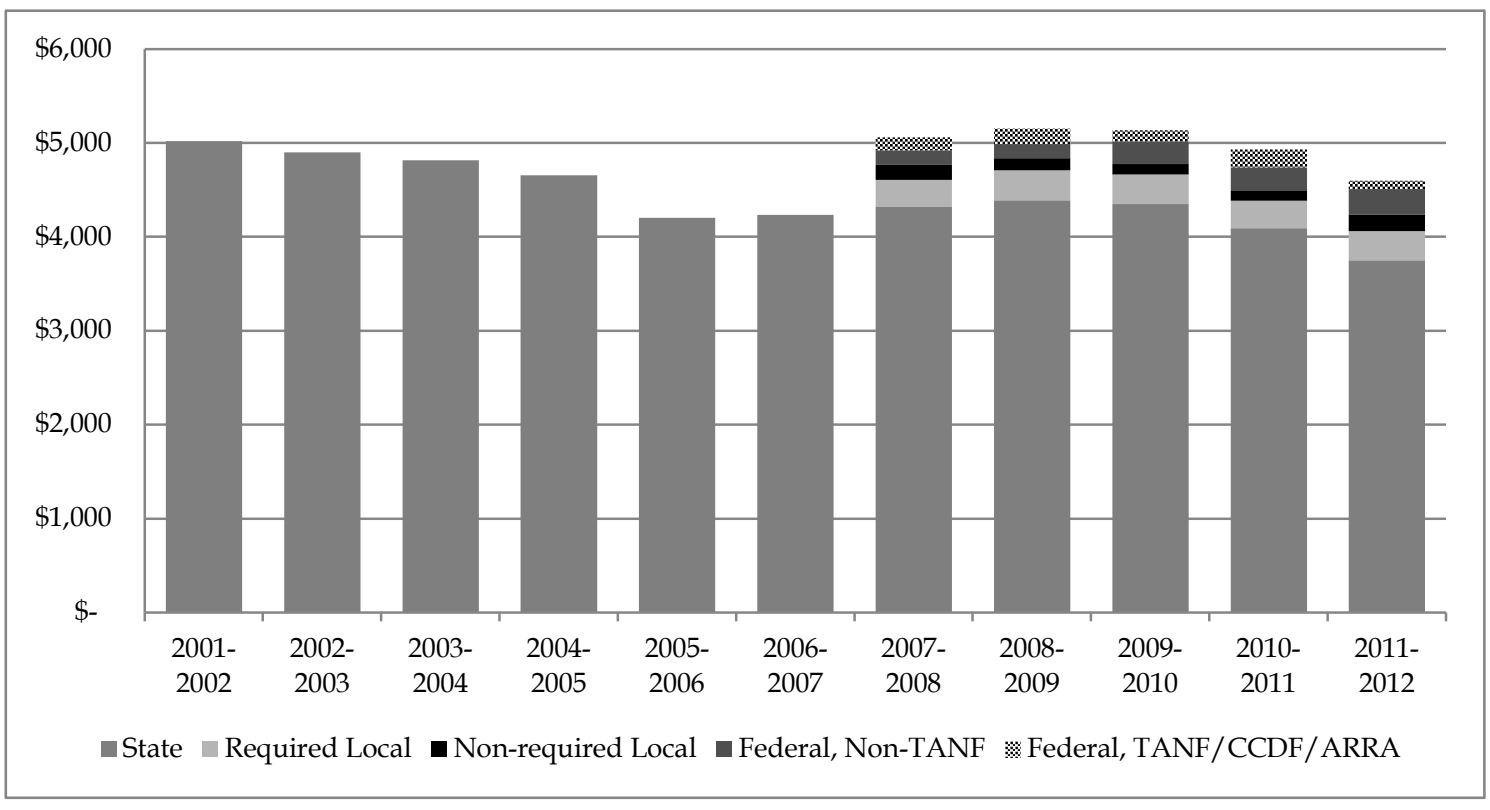

Figure 2. State spending on pre-K 2001-2002 to 2011-2012

preschoolers at age 4 and half those provided no support for pre-K.

\section{Resources}

In inflation-adjusted 2011 dollars, state spending increased from $\$ 3.47$ billion in 2001-2002 to $\$ 5.12$ billion in 2011-2012, a 48 percent increase. Figure 2 displays annual spending in constant 2011 dollars as well as nominal dollars for each year. Growth in total spending was slow at the beginning of the decade and picked up mid-decade during that period of more rapid enrollment growth before dropping as the recession reduced state revenues. As Figure 2 shows, the recent decline in real spending was the first we recorded. Indeed, the drop was so steep that even nominal dollar (unadjusted for inflation) spending by states dropped in 20112012, and this was not made up by increases from other sources. Federal stimulus funds were drying up, and local governments were cutting back spending. A return to trend that makes up for lost ground will require a substantial increase in spending, as Figure 2 also makes clear.

Despite the $\$ 1.65$ billion increase in state funding, enrollment growth outpaced spending growth over the decade. As a result, the amount spent by states per child decreased in constant dollars from $\$ 5,020$ to $\$ 3,841$, a drop of $\$ 1,179$ per child, or 23 percent. This is a huge decline and not just the introduction of efficiencies. Annual spending per child is reported below in Figure 3. As can be seen, some effort had been made to reverse the decline before the nation entered the recession. 


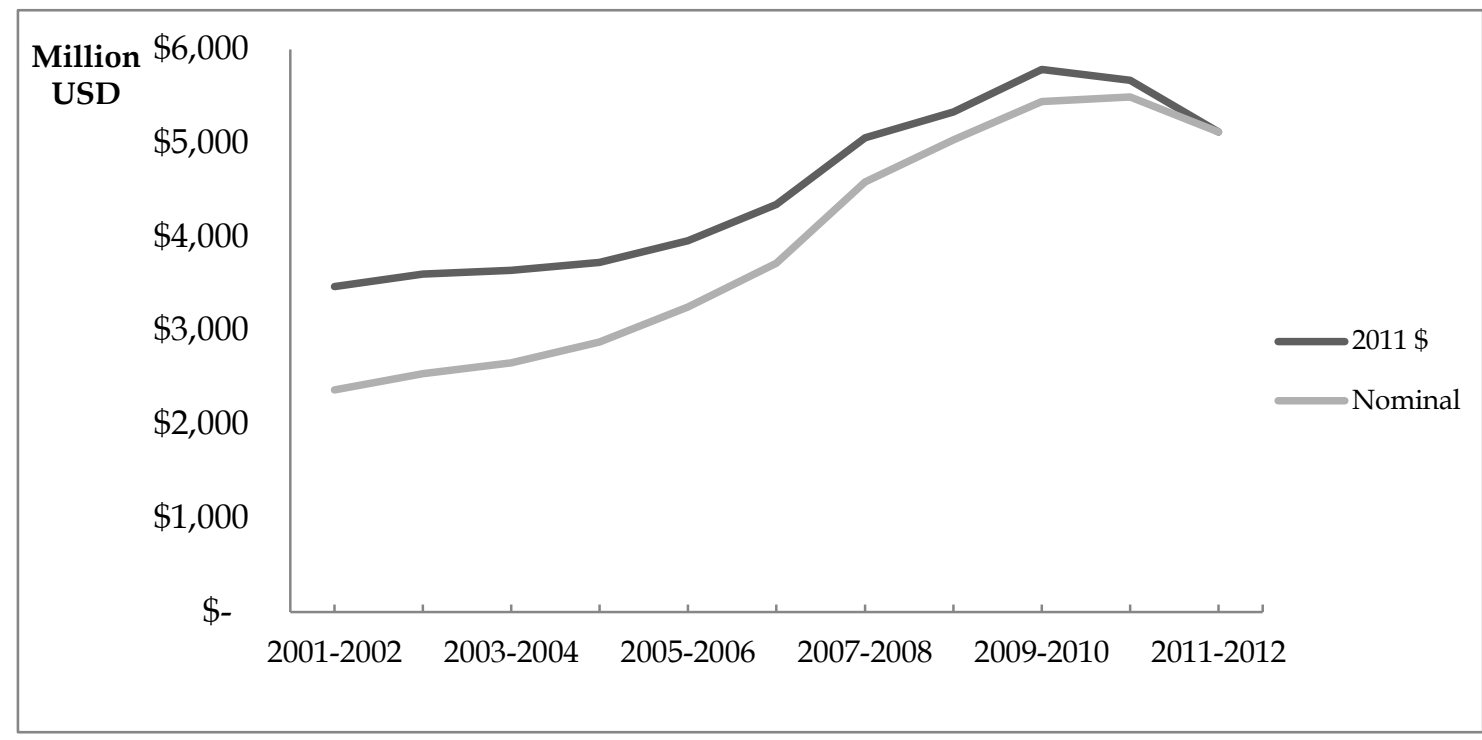

Figure 3. Spending per child by source 2001-2002 to 2011-2012 (in 2011 USD currency)

As state revenues faltered, policies shifted and spending fell by more than $\$ 500$ million drop from 2010-2011 to 2011-2012 alone.

Beginning with 2007-2008, we obtained more reliable data from states on funding from other sources. This remains incomplete, as many states cannot report it fully or, sometimes, at all. Yet, it is important to understand that state pre-K is not entirely statefunded everywhere. In fact, the majority of states rely on local funding to some extent. In some states, funding basically operates in the same way for pre-K as it does for K-12 with state and local governments both assuming substantial shares. In a small number of states, it is largely or entirely state supported. Other funding streams tapped to help pay for early education programs include federal funds under state or local control-Temporary Aid for Needy Families (TANF), Child Care
Development Fund (CCDF), and Title I of the Elementary and Secondary Education Act (ESEA), for example. Some states require formula-based matching contributions from local schools. In others, local school districts do not have a mandated contribution. Recognizing that the numbers are incomplete, Figure 3 shows that nonstate spending per child was reported to be about $\$ 740$ in the 2007-2007 year and rose to $\$ 845$ in the 2011-2012 year. This change may represent better reporting as well as states turning more to other sources of funds during the recession. Required local funding is the largest reported source of reported nonstate spending.

\section{Program Standards}

Funding per child is one important indicator of state support for quality 
pre-K. States also support quality by setting standards. The Yearbook surveys states regarding a wide range of program standards and NIEER highlights information on ten quality standards in that annual report. As a guide to how well states perform in this regard, NIEER compares state standards against 10 benchmarks. These benchmarks are based on evidence and the positions of professional groups such as the National Association for the Education of Young Children.

The only study providing direct observations of quality for a national sample of programs indicates that lack of quality is a serious problem. Only about 1 in 3 classrooms serving 4-yearolds was rated good or better on the Early Childhood Environment Rating Scale (Snyder \& Dillow, 2012; Harms, Clifford, \& Cryer, 1998). Recent studies indicate that quality has a larger impact on children's learning and development when it is good or better while improvements from low to moderate quality contribute less (Burchinal, Vandergrift, Pianta, \& Mashburn, 2010). Classrooms in public programs (which must meet higher standards) were more likely to be good or better and less likely to be of low quality than those in private programs.

Our information on program standards should be interpreted carefully. We would not assert that each and every benchmark must be met by a program to produce good results. Nor are all of the benchmarks equally important. We also recognize that it is possible to meet the letter of the law while violating its spirit (for example, if funding is too low to provide adequate compensation, teachers may obtain meaningless degrees from diploma mills). However, the preschool programs found to produce large gains in learning and development typically met or exceeded these benchmarks, while those that failed to produce substantial gains have not met these benchmarks (Barnett, 2003; Bowman, Donovan, \& Burns, 2001; Pianta, Barnett, Burchinal, \& Thornburg, 2009; Shonkoff \& Phillips, 2000).

NIEER's Quality Standards Checklist overall is best regarded as a set of minimum standards for programs that are intended to produce substantive improvements in learning and development (Barnett, Carolan, Fitzgerald, \& Squires, 2012). The checklist is not an exhaustive inventory of all of features of such a high-quality program. However, lax standards with respect to the program features covered risk losing the expected gains from preschool programs. Benefit-cost analyses have indicated that the returns to preschool programs with standards that are much stricter and more costly standards than set by our benchmarks far exceed their cost. Therefore, it is likely that states risk far larger losses in future benefits from lower standards than they can expect to save through reduced costs (Barnett \& Masse, 2007).

Finally, we emphasize that the benchmarks are applied to state policies. Actual practice may vary from state policy (though if it is evident that 
programs widely violate policy with state knowledge we do not give credit). Where policies do not meet benchmarks, it is still possible for many and sometimes even most programs in a state to meet those benchmarks. Some states do not impose standards regarding some program features because of issues regarding local school district autonomy. More often than not, however, a lack of state standards or low standards reflects an unwillingness to adequately fund programs to meet the standards.

The Yearbook's 10 quality standards with their respective benchmarks are:

- Teacher degree: Must have a bachelor's degree;

- Teacher training: Must have specialized preparation in preschool education;

- Assistant teacher qualification: Must have a Child Development Associate (CDA) or equivalent credential;

- Professional development: Teachers must receive at least 15 hours of annual in-service training;

- Class size: May not exceed 20 children;

- Ratio: May not exceed 10 children per staff member;

- Early learning standards: Comprehensive standards as specified by the National Education Goals Panel for physical well-being and motor development, social/emotional development, approaches toward learning, language development, and cognition and general knowledge;

- Comprehensive services: Vision, hearing, and health screenings and referrals as well as at least one service such as home visits, parent education, or nutrition information;

- Nutrition: Provision of at least one meal; and

- Monitoring quality: all sites are visited to assess program quality at least once every five years.

As seen in Figure 4, states generally improved pre-K program standards over the last decade. In fact, the percentage of programs meeting NIEER benchmarks increased for 8 of the 10 policies even though the number of programs increased. Progress was more pronounced prior to the Great Recession, after progress tended to stall or even to be reversed. Most striking is the widespread adoption of comprehensive Early Learning Standards. While only 36 percent of programs had such standards in 2001-2002, by 2011-2012 Ohio was the only state (funding pre-K) that did not yet meet this benchmark. Ohio adopted comprehensive early learning standards for 2012-2013, making this the first benchmark to see a 100 percent adoption rate.

With respect to two benchmarks, states ended the decade below where they started-meals and site visits. In 2001-2002, 50 percent of programs nationally required at least one daily meal for all pupils; that fell slightly to 46 percent by 2011-2012. The percent of programs requiring meals actually dropped to just 40 percent in the 20072008 year, so the current 46 percent is a 


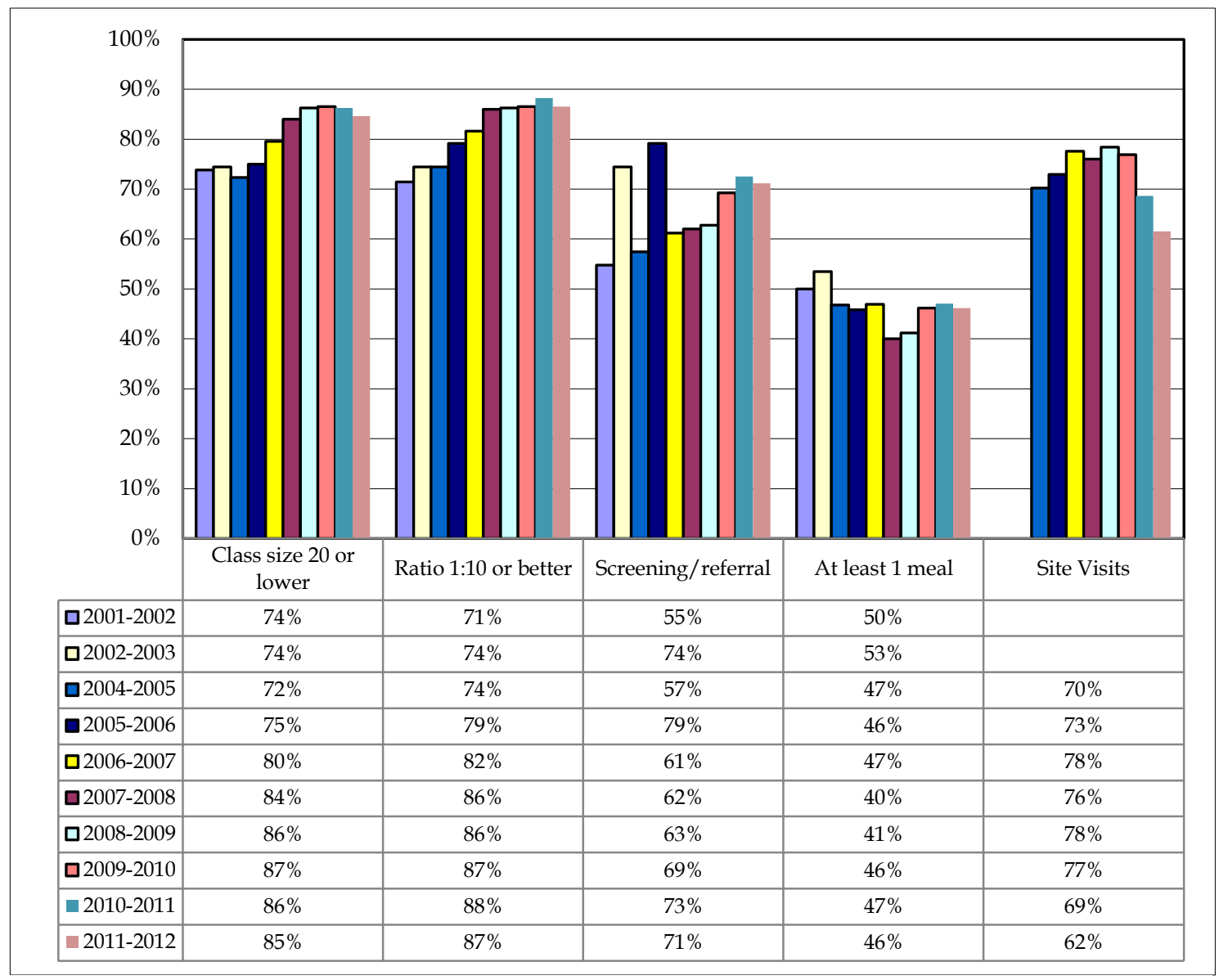

Figure 4. Benchmark changes 2001-2002 to 2011-2012 (1)

slight increase over just a few years ago. Although this is at best a crude indicator of program support for nutrition, the decline took place despite an increase in need as families experienced more food insecurity due to the impacts of the recession.

NIEER began tracking state pre-K program quality monitoring (defined as making site visits to assess quality, not safety, on a regular schedule for all sites) in 2004-2005. At that time, 70 percent of programs met the requirement. After rising to 78 percent of programs in 2008-2009 it fell to 62 percent of 2011-
2012. Conversations with state officials indicate that this decline can be directly linked to tightened state budgets due to the recession. Unfortunately, research indicates that classroom observation linked to coaching and professional development is a key element of a system for continuous improvement of quality. Without actual observation it is difficult for states to know if standards are being implemented as intended or to assess the extent to which resources are being effectively employed.

Also notable are the benchmarks on which progress stalled after earlier 


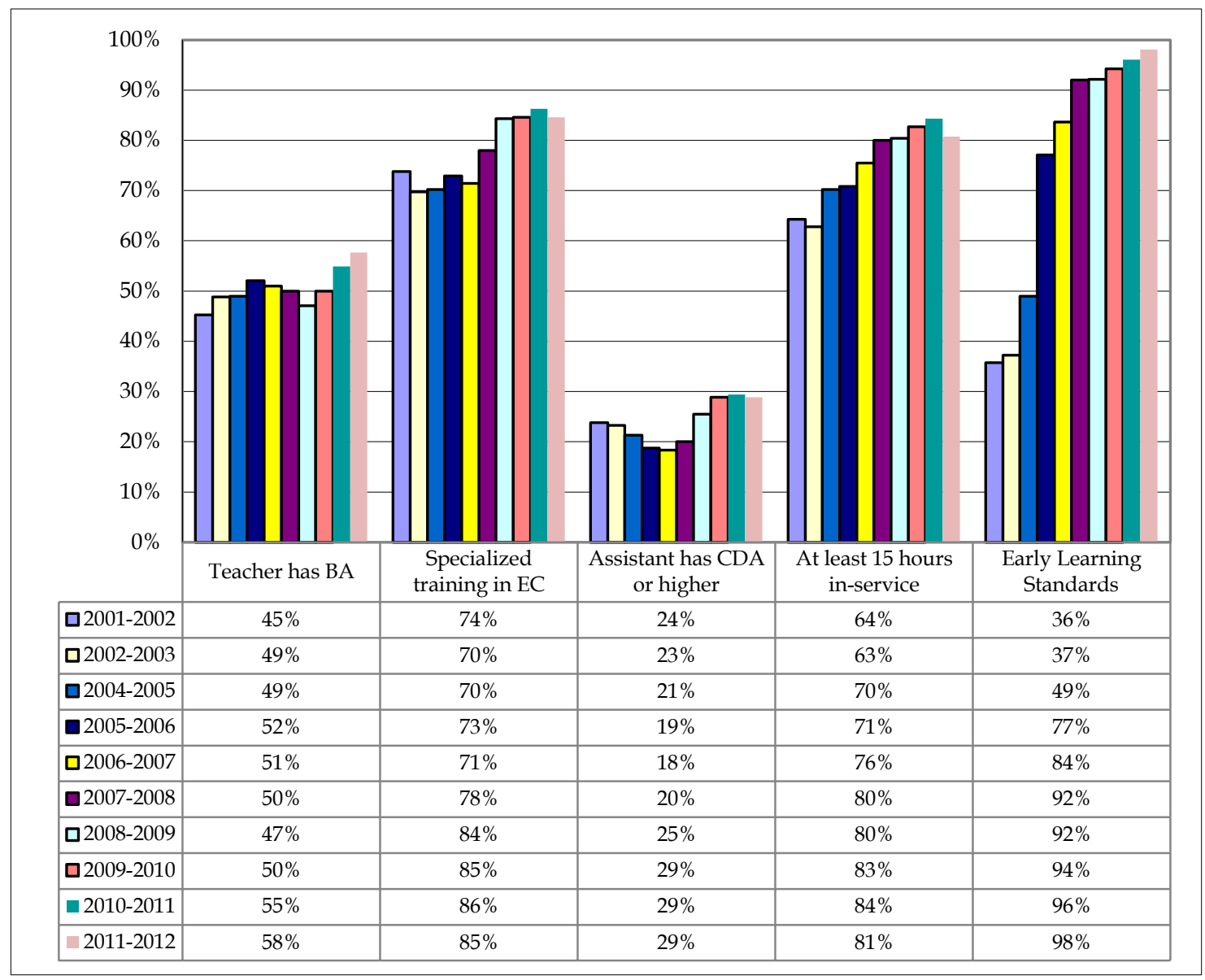

Figure 5. Benchmark changes 2001-2002 to 2011-2012 (2)

improvements. Requiring lead teachers to have specialized training in early childhood education was originally only a policy in 74 percent of programs; this had improved to 84 percent of programs by 2008-2009. However, in the three years since, this percentage has changed little. Requiring assistant teachers to have at least a CDA has fared even worse, starting at 24 percent of programs in 2001-2002, falling to just 18 percent in 2006-2007 year, and rising back to just 29 percent of programs.

Although a number of factors including state philosophy about local control can determine state quality standards, cost looms among the most salient. Requirements for higher teacher control can determine state quality standards cost looms among the most salient. Requirements for higher teacher credentials are particularly strong drivers of costs, so state policy makers are hesitant to increase these requirements when budgets are stretched thin. Many states report that while certain standards are not required through policy, the standards are met by most 
classrooms. For example, policies regarding meals often depend on the length of program day, with part-day programs only required to serve snacks, but part-day classrooms are said to exceed this requirement often. Similarly, in some states that do not require all teachers to have a BA degree, the vast majority may have a $\mathrm{BA}$ or higher degree.

\section{Teacher Qualification and Compensation}

Although some progress has been made toward increasing the quality and qualifications of teaching staff, much remains to be done. More state pre- $\mathrm{K}$ programs now require lead teachers to have a bachelor's degree, increasing from 45 percent to 58 percent. Eightyfive percent of programs now require lead teachers to have specialized training in early childhood, up from 74 percent a decade ago.

In 2012 we asked for the first time about the actual number of lead teachers holding each degree in the state-funded pre-K program. Thirtytwo programs were able to report this breakdown for a total of 44,810 teachers, though assuming an average class size of 20, state-funded pre- $\mathrm{K}$ programs nationwide employ closer to 66,600 teachers. Of those teachers whose degree can be reported, 79 percent of lead teachers have a BA or higher $(60 \%$ BA, $19 \%$ MA or higher). Of teachers who don't have a BA, more have a
CDA (15\%) than have an AA (6\%). Taking into account the numbers of children served by various states, it remains the case that most children enrolled in state pre-K attend programs in which teachers are not required to have a bachelor's degree and assistants need only a high school diploma. The high percentage of teachers with a BA suggests that even in states that do not require the $\mathrm{BA}$ most teachers have the degree. So requiring a BA would impact a relatively small percentage of teachers.

Children also interact with assistant teachers in pre-K settings, and here much less progress has been made in improving education requirements. NIEER's benchmark for assistant teachers is that they must hold a Child Development Associate (CDA) or equivalent, a credential requiring coursework in early childhood education or a related field on top of a high school degree. The percentage of programs requiring assistant teachers to have a Child Development Associate (CDA) credential has remained below 30 percent for a decade. This likely reflects the lack of importance attributed to assistant teachers by policy makers (and others, as there is relatively little research on assistant teachers).

Perhaps the most fundamental issue relating to raising teacher quality is compensation. Without adequate pay, raising requirements for qualifications can result in little more than meaningless credentials. In the market for good teachers, pre-K programs 
Table 1. Lead Teacher Salary Ranges in Public and Private Settings, 2008-2009

\begin{tabular}{|c|c|c|c|c|}
\hline \multirow{2}{*}{$\begin{array}{l}\text { Lead teacher salary distribution } \\
\text { (As of 2008-2009 school year) } \\
\$ 20,000-\$ 24,999\end{array}$} & \multicolumn{2}{|c|}{ Public } & \multicolumn{2}{|c|}{ Private } \\
\hline & 1 & $2 \%$ & 1 & $2 \%$ \\
\hline$\$ 25,000-\$ 30,000$ & 1 & $2 \%$ & 3 & $6 \%$ \\
\hline$\$ 30,000-\$ 34,999$ & 3 & $6 \%$ & 7 & $14 \%$ \\
\hline$\$ 35,000-\$ 39,999$ & 4 & $8 \%$ & 3 & $6 \%$ \\
\hline$\$ 40,000-\$ 44,999$ & 3 & $6 \%$ & 0 & $0 \%$ \\
\hline$\$ 45,000-\$ 39,999$ & 7 & $14 \%$ & 1 & $2 \%$ \\
\hline$\$ 50,000-\$ 54,999$ & 2 & $4 \%$ & 1 & $2 \%$ \\
\hline$\$ 55,000-\$ 59,999$ & 1 & $2 \%$ & 0 & $0 \%$ \\
\hline$\$ 60,000-\$ 64,999$ & 1 & $2 \%$ & 1 & $2 \%$ \\
\hline Data not available & 27 & $54 \%$ & 33 & $66 \%$ \\
\hline
\end{tabular}

Note. In 7 of these programs, public and nonpublic teachers are paid on the same pay scale.

Table 2. Pre-K Teachers Paid On Public School Salary Scale, 2009-2010

Are teachers required to be paid on public school salary scale? (2009-2010 school year)

\begin{tabular}{c|c|c}
\hline Yes & 16 & $31 \%$ \\
\hline No & 14 & $27 \%$ \\
\hline Yes (public); No (nonpublic) & 20 & $39 \%$ \\
\hline Not reported & 1 & $2 \%$ \\
\hline
\end{tabular}

must compete with $\mathrm{K}-12$ and preschool special education in the public schools, and other better paying fields. Yet, teacher compensation is a big driver of cost per child. According to 2009 data from the Bureau of Labor Statistics, the average annual salary for a Preschool teacher (not including special education) was $\$ 27,450$, compared to $\$ 50,380$ for a Kindergarten teacher and \$53,150 for Elementary School teachers generally. ${ }^{1}$ The 2008-2009 survey collected information from states about teacher pay. As shown in Table 1, in programs able to report salary range for Pre-K teachers in public settings, 83 percent were paid below $\$ 50,000$; in nonpublic settings, 88 percent were below that level. The majority of programs were unable to report this information which is why we stopped collecting it. These data indicate that the median salary for teachers in public school settings was $\$ 40,000$ to $\$ 44,999$, while that for those in private was $\$ 30,000$ to $\$ 34,999$. This is similar to results from a 2010 survey of preschool teachers by NIEER which found an average salary of just over $\$ 40,000$ for teachers in state and locally funded public pre-K programs.

In 2009-2010, 31 percent of programs reported that teachers in the statefunded pre-K program were paid on the public school salary scale as shown 
Table 3. Enrollment by Schedule, Fall 2011

\begin{tabular}{c|c}
\hline Extended day & $5 \%$ \\
\hline School day & $25 \%$ \\
\hline Part day & $39 \%$ \\
\hline Determined locally & $19 \%$ \\
\hline Not available & $12 \%$ \\
\hline
\end{tabular}

in Table 2. Another 39 percent reported that the public school pay scale applied to teachers in public schools but not in private settings.

All but one of the others (27\%) reported that the public school pay scale for K-12 teachers did not apply to pre-K teachers.

Assistant teachers appear to be paid even more poorly than teachers, though most states could not report these data.

In the 2008-2009 survey no state reported an average starting salary for an assistant teacher above the $\$ 25,000$ to $\$ 30,000$ range. In all settings, the most commonly reported pay rate for assistant teachers was $\$ 15,000$ - \$24,999. Only 8 programs reported the same pay scale applied in public and nonpublic settings funded by state pre-K.

\section{Length of Program Day}

Policies regarding the length of preschool program day vary widely from state to state. As state policies do not even define half and full-day consistently, we impose the following definitions to discuss hours of service; Extended day: 8 or more hours; School day: more than 4 hours, fewer than 8 ;
Part day: fewer than 4 hours. Just over 60 percent of state programs leave length of day entirely up to local discretion or offer a choice of schedules, usually part or school day. Another 19 percent offers only a part-day, 19 percent more requires a school day, and 2 percent (one program) has an extended day.

States often can report the operating schedules their children experience and the percentage of children experiencing each schedule is displayed in Table 3. Even where programs can determine their own schedules locally, states are often able to report the actual operating schedules provided. Of the 1.3 million children enrolled in state-funded pre-K in 2011-2012, nearly 40 percent were in a program operating only on a part-day schedule, with another 25 percent on a full school-day schedule. Only 5 percent of students were reported to have extended-day schedules, though administrators note that if extendedday services are provided in conjunction with a partner, states may not have that information. Twelve percent of pre-K students have daily schedules that are determined locally and not reported to the state. 


\section{Program Evaluation}

Of the 53 programs (including two in the District of Columbia) profiled in the 2011-2012 Yearbook, 31 (57 percent) reported that their program had recently undergone a formal evaluation of program quality and/or effectiveness. Forty-three percent reported that programs had been evaluated for both the quality of education they provide and the effectiveness of that education in terms of improving children's learning and development. On the other hand, over 40 percent had not been evaluated recently.

NIEER has asked about program evaluations since the 2006-2007, but is a topic for which we have yet to fully refine our questions. NIEER does not specify what constitutes an evaluation or what counts as "recent." Most programs provide additional details that provide clarifications. As a result, we know that many programs report the collection of descriptive statistics compiled for an annual report as an evaluation. Few specify a research design or methodology, or report specific measures used for evaluation. Hence, it is difficult to draw conclusions regarding the rigor of program evaluations, but our best judgment is that few permit strong conclusions about program impacts on learning and development.

Of the 31 programs with an evaluation, 29 percent reported that evaluations were "ongoing and/or planned," and another 23 percent reported that they conduct evaluations annually. Another 36 percent reported conducting evaluations since 2010. This indicates that evaluation is an active concern for about half of state pre-K programs. Eighteen programs (58 percent of those conducting evaluations) indicated that the evaluation was mandated by the state, while another 13 (42 percent of those with evaluations) indicated it was not.

The percent of programs reporting that an evaluation was conducted has actually gone down in recent years. It was 80 percent in 2006-2007 and it declined steadily to 57 percent in 20112012. To some extent the decline could reflect the impact of the recession. However, it also may reflect a better understanding by states as to what really constitutes an evaluation.

These data indicate the need for additional supports to states regarding pre-K program evaluation. States could benefit from technical assistance pertaining to best practices in conducting and using program evaluation. Undoubtedly, states could also benefit from additional funds to support rigorous evaluations. The cuts to site visit requirements coupled with a decline in programs reporting a recent evaluation indicates that state monitoring is slipping, creating a lack of meaningful information on how programs actually operate. 


\section{Broader Policy and System Issues}

\section{English Language Learners and Hispanic Students}

High quality early education has been found to be particularly effective in improving the learning and development of English Language Learners, the vast majority of whom are Hispanic in the United States (FiguerasDaniel \& Barnett, 2013). One in 7 children starting kindergarten has a primary language other than English. Limited English language proficiency at kindergarten entry is associated with low achievement and other poor schooling outcomes for Hispanic students. Only 18 percent of Hispanic children demonstrate proficiency in reading and 24 percent in math at fourth grade, and only 63 percent graduate from high school. Yet despite their greater need, Hispanic children attend preschool at much lower rates than children from other ethnic groups even though surveys of find Hispanic parents eager to enroll their children in preschool education if it is available.

Over half of Hispanic 3 and 4-yearolds nationwide reside in just three states: California, Texas, and Florida. Thus, the preschool policies of these states are particularly important for Hispanics. Florida offers virtually universal coverage at age 4 between state funded pre-K and Head Start. Texas enrolls about half of all 4-yearolds and a small percentage at age 3 . California enrolls less than 1 in 5 children at age 4 , and half that many at 3. So access varies greatly across the states and is worst in the largest state. However, of even greater concern is that all 3 states programs meet fewer than half of the quality standards benchmarks, and in key respects their standards are abysmal. Florida requires no educational qualifications of teachers beyond a high school diploma. Texas has no limits on class size or ratio and teachers in private programs need no college degree or specialized training. California requires teachers to have a two year degree and limits the

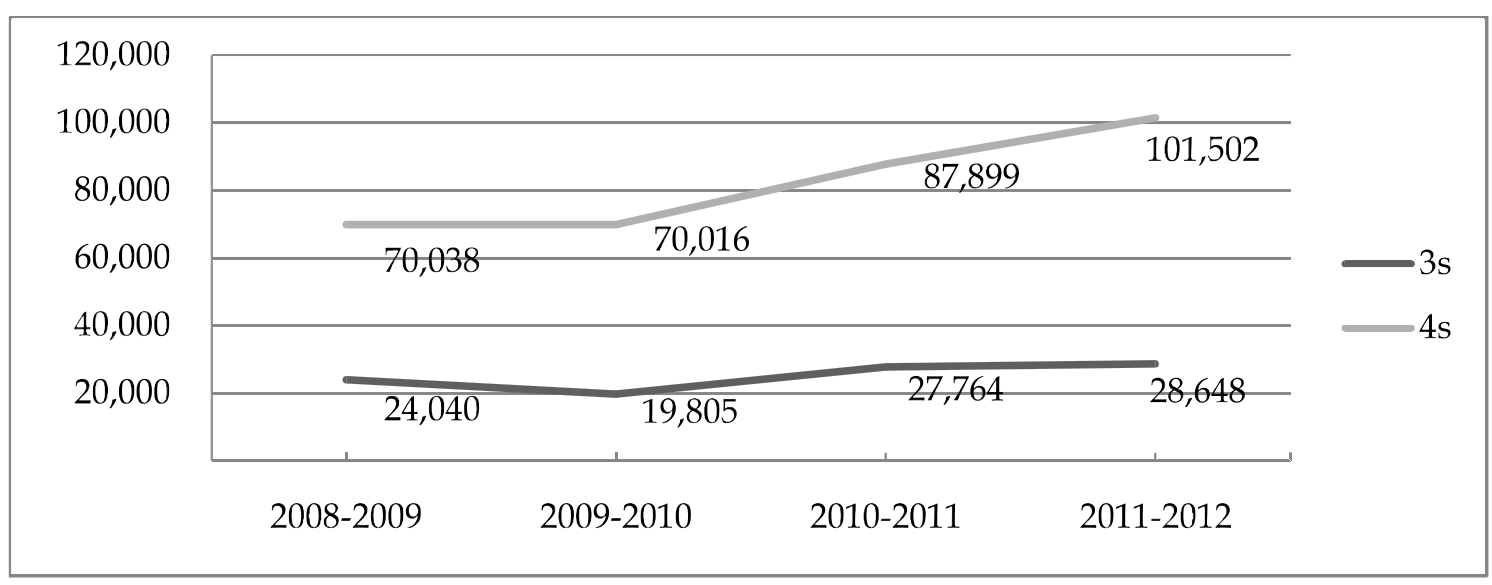

Figure 6. Enrollment of children with IEPs in state-funded pre-K 
ratio of children to adults, but does not limit class size.

\section{Enrollment of Children with Special Needs in Pre-K}

Quality preschool education is particularly important for children with disabilities. Enrollment in a good preschool program increases the likelihood of early identification of special needs and the provision of appropriate services. In addition, state pre-K programs are an important means for serving children who have special needs in the least restrictive environment together with peers who provide increased opportunities for language and social development.

In 2011-2012, programs reported serving at least 196,349 students with special needs (requiring Individualized education plans or IEPs) in state-funded pre-K, though they could provide age breakdowns for only about half of these children. These age breakdowns indicated it is largely 4-year-olds (82\%) who receive both special education services and state-funded pre-K. Threeyear-olds comprise 16 percent of pre-K students who have IEPs. Two percent are 5-year-olds with many states permitting children with special needs to enroll in pre-K at this age.

In 2011-2012, 14 programs (26\%) reported that while children with IEPs were enrolled in state-funded pre-K, the state could not provide the exact number of children served. Another 3 programs $(6 \%)$ can report the total number of special education students served in the program but cannot confirm the age breakdown. We estimated the numbers of 3- and 4-year-olds with special needs served in state pre-K across all states by assuming that the states not reporting these numbers had the same patterns of enrollment as those who were able to report this detail. Figure 6 displays those estimates beginning with 2008-2009.

It appears that state pre-K has increased the enrollment of students with special needs over the years, particularly for 4-year-olds. The enrollment of 4-year-olds who have IEPs increased by over 30,000 from 2008-2009 to 20112012. That enrollment in state pre-K has not changed much for 3-year-olds with special needs is not surprising given that regular state pre-k services at that age have remained rare. There is some effort to prioritize enrollment of children with special needs; of the 30 programs that use risk factors to determine eligibility, 70 percent reported in 2011-2012 that child developmental delay or disability was one of the risk factors.

\section{Progress toward Educational Alignment}

As state-funded pre-K has among its chief goals preparing young learners for school success, efforts to align early education with children's later educational experiences in the elementary grades are important. Each year we have asked states whether they require their programs to provide "transition to K activities". States don't provide specific details as to what these services 
involve, but the percent of states requiring transition services increased from 65 percent to 77 percent over the last decade.

\section{Conclusions and Implications for Policy}

The past decade of state pre-K policy in the United States was characterized by both dramatic change and remarkable stability. Enrollment increased dramatically for 4-year-olds over the decade, doubling from 14 percent to 28 percent of the population. The federal Head Start program was for decades the most salient public support for preschool education, but it has been eclipsed by state-funded pre-K which serves far more children, especially at age 4 . In some states, preschool is virtually universal at age 4; 8 states and the District of Columbia serve the majority of 4-year-olds. Yet, there is tremendous variability across the states. Interstate inequalities have increased as some states moved forward dramatically while others continue to offer no program at all. And, there has been remarkable stability in at least one respect. Enrollment at age 3 changed very little, and much of the enrollment growth at this age may have been contributed by increased preschool special education enrollment.

Perhaps the most negative trend over the decade was the decline in state expenditure per child of more than $\$ 1,000$ adjusting for inflation. This is partly due to a long-term tendency to expand enrollment faster than expenditure, but the problem was greatly exacerbated by the Great Recession. Half of the decline in state spending for pre-K took place in 20112012 after federal economic stimulus funds were largely gone. As state revenues recover, it will be important to track state progress in restoring pre$\mathrm{K}$ funding to more adequate levels. This poses a serious challenge because: it is likely to be some years before state revenues fully recover; states must repair other damage from the economic storm including expenditures for pension fund payments and infrastructure repairs that were put off; economic growth is likely to remain low by historical standards; and, rising costs in other areas including health care will continue to squeeze state budgets (U.S. Government Accountability Office, 2013; Oliff, Mai, \& Palacios, 2013).

Despite the decline in funding per child, for most of the decade there was a strong trend toward improvement in early learning standards and moderate improvement in program quality standards generally. This trend continues with respect to early learning standards, which are being aligned with new K-12 standards in most states. Policy makers seem to recognize the need for continuity across the years. In the United States, disadvantaged children in particular have high mobility rates and it is difficult to provide them with educational continuity without some consistency in curriculum from place to 
place (Rumberger, 2003). However, progress with respect to some more costly program standards stalled or was even reversed during the recession.

Teacher and teacher assistant qualifications requirements and compensation in state preschool programs remain low relative to other professions and compared to that in the public schools. There is considerable debate over the value of raising qualification requirements with some arguing that this will have no effect on program effectiveness and others arguing that highly qualified teachers are one key ingredient of a highly effective (Zigler, Barnett, \& Gilliam, 2011). Policy maker reluctance to raise qualifications is primarily due to cost. However, many state pre-K teachers already exceed the qualifications requirements of their programs. Requiring a BA degree of all teachers would affect relatively few teachers, and bringing all teachers up to that level might have only minimal impact on average per pupil cost.

However, simply raising teacher qualifications requirements without increasing compensation to more competitive levels is likely to fail to accomplish the ultimate goal which is to attract and keep higher performing teachers. Providing teacher pay parity with K-12 education would address the underlying problem. How much would this cost? Just returning the per pupil expenditure to its level a decade ago would add about $\$ 20,000$ to pre-K teacher compensation per classroom. This appears to be more than enough to bring about parity with $\mathrm{K}-12$ based on the teacher salary figures reported by state pre-K administrators.

As state pre-K programs often are not equal partners in many state education systems and there is no overall federal responsibility of any kind for such programs, much of the data we expect to be available on education programs is not collected for pre-K. Most obviously, total public expenditures on such programs are unknown in many states. In addition, states often cannot report enrollment rates by family income, ethnicity, or language making it difficult to evaluate the extent to which the most disadvantaged children access such programs.

Even from the limited data available it is apparent that access to good preschool education is highly variable and unequal within and among states. Some groups who might benefit most from such programs have the least access, such as English language learners and Hispanic children. They are concentrated in states with particularly low standards and poorly qualified teachers despite the greater difficulty of teaching such children well. The highly variable quality of state pre-K also creates problems for the education of children with disabilities alongside their more typically developing peers, as far too few teachers are presently capable of providing the quality education expected for children with special needs.

States invest in preschool education with the goal of enhancing the learning 
and development of young children, particularly the most disadvantaged. However, most of them have no way of knowing the extent to which they achieve this goal. Many states report conducting evaluations, but these are not always rigorous and funding for monitoring and evaluation, tenuous in the best of times, was hurt by the recession. In some states, policy makers appear to believe that simply testing children at kindergarten entry (or, less often at entry to preschool, as well) provides a basis for assessing the program's quality and effectiveness. Unfortunately, while such data may be useful, estimating the program's contribution to learning and development is more complex and difficult than simply looking at test scores or test score gains. Most states have very limited capacity to oversee and support program evaluation, and during the recession this capacity was reduced. This is a cause for serious concern.

Recently, the Obama administration has proposed federal support for statefunded pre-K that addresses many of the concerns raised by our review of progress over the past decade including the lingering impacts of the Great Recession. The plan offers states matching funding if they increase expenditures on pre-K over the next 10 years, with a particular emphasis on serving all children under 200 percent of the federal poverty level (which is about half of all children in the United States, with added incentives to serve all children). The administration's proposal is a conservative approach to federal pre-K policy in that it is temporary and does not create a permanent federal role in preschool. A 10 year period of support for expanding and improving state pre- $\mathrm{K}$ can be viewed as assisting states in moving forward at a time when they continue to suffer from the effects of the recession on revenues and delayed spending on pension funds, infrastructure, and other needs. Whether such a policy is sufficient to develop high-quality pre-K for all children throughout the states is something that our survey will monitor, should the proposal or something like it become law.

\section{References}

Barnett, W. S. (1998). Long-term effects on cognitive development and school success. In W. S. Barnett \& S. S. Boocock. (Eds.). (1998). Early care and education for children in poverty: Promises, programs, and long-term results (pp. 11-44). NY: State University of New York Press, Albany.

Barnett, W. S. (2003). Better teachers, better preschools: Student achievement linked to teacher qualifications. Preschool Policy Matters, 2. New Brunswick, NJ: National Institute for Early Education Research.

Barnett, W. S., \& Masse, L. N. (2007). Early childhood program design and economic returns: Comparative benefit-cost analysis of the Abecedarian program and policy implications, Economics of 
Education Review, 26, 113-125.

Bowman, B. T., Donovan, M. S., \& Burns, M. S. (Eds.). (2001). Eager to learn: Educating our preschoolers. Washington, DC: National Academy Press.

Burchinal, M. R., Cryer, D., Clifford, R. M., \& Howes, C. (2002). Caregiver training and classroom quality in child care centers. Applied Developmental Science, 6, 2-11.

Burchinal, M., Vandergrift, N., Pianta, R., \& Mashburn, A. (2010). Threshold analysis of association between child care quality and child outcomes for lowincome children in pre-kindergarten programs. Early Childhood Research Quarterly, 25(2), 166-176.

Figueras-Daniel, A. \& Barnett, W. S. (2013). Preparing young Hispanic dual language learners for a knowledge economy. New Brunswick, NJ: National Institute for Early Education Research.

Harms, T., Clifford, R., \& Cryer, D. (1998). Early Childhood Environment Rating Scale (Rev. ed.). New York: Teachers College Press.

Oliff, P., Mai, C. \& Palacios, V. (2013). States continue to feel recession's impact. Washington, DC: Center on Budget Priorities.

Pianta, R. C., Barnett, W. S., Burchinal, M., \& Thornburg, K. R. (2009). The Effects of Preschool Education What We Know, How Public Policy Is or Is Not
Aligned With the Evidence Base, and What We Need to Know. Psychological Science in the Public Interest, 10(2), 49-88. Rumberger, R. W. (2003). The causes and consequences of student mobility. Journal of Negro Education, 72(1), 6-21.

Shonkoff, J. P., \& Phillips, D. A. (Eds.). (2000). From neurons to neighborhoods: The science of early childhood development. Washington, DC: National Academy Press.

Snyder, T. D. \& Dillow, S. A. (2012). Digest of Education Statistics 2011 (NCES 2012001). Table 57. National Center for Education Statistics, Institute of Education Sciences, U.S. Department of Education. Washington, DC.

U.S. Government Accountability Office. (2013). State and local governments' fiscal outlook. April 2013 update. Washington, DC: USGAO. http://www.gao.gov/assets/ 660/ 654255.pdf

Zigler, E., Barnett, W. S., \& Gilliam, W. (Eds.) (2011). The Pre-K Debates: Current Controversies and Issues. Baltimore: Brookes Publishing.

\section{Notes}

1 Occupational Employment and Wages, May 2009. Bureau of Labor Statistics 25-2011, 25-2012, 25-2021. http://www.bls.gov/oes/2009/may/oes252011.htm http://www.bls.gov/oes/2009/may/oes252012htm http://www.bls.gov/oes/2009/may/oes252021.htm 